This is the peer reviewed version of the following article: Angew. Chem. Int. Ed. 2016, 55, 2764-2767, which has been published in the final form at http://onlinelibrary.wiley.com/doi/10.1002/anie.201510540/full. This article may be used for noncommercial purposes in accordance with Wiley Terms and Conditions for Self-Archiving :

(https://authorservices.wiley.com/author-resources/Journal-Authors/licensing-open-access/open-access/self-archiving.html)

\title{
Cooperative Reductive Elimination: The Missing Piece in the Oxidative Coupling Mechanistic Puzzle
}

\author{
Ignacio Funes-Ardoiz, ${ }^{[a]}$ and Feliu Maseras ${ }^{*[a, b]}$
}

\begin{abstract}
The reaction between benzoic acid and methylphenylacetylene to form an isocoumarin is catalyzed by $\mathrm{Cp}{ }^{*} \mathrm{Rh}(\mathrm{OAc})_{2}$ in the presence of $\mathrm{Cu}(\mathrm{OAc})_{2}\left(\mathrm{H}_{2} \mathrm{O}\right)$ as an oxidant and a leading example of oxidative-coupling reactions. Its mechanism was elucidated by DFT calculations with the B97D functional. The conventional mechanism, with separate reductive-elimination and reoxidation steps, was found to yield a naphthalene derivative as the major product by $\mathrm{CO}_{2}$ extrusion, contradicting experimental observations. The experimental result was reproduced by an alternative mechanism with a lower barrier: In this case, the copper acetate oxidant plays a key role in the reductive-elimination step, which takes place through a transition state containing both rhodium and copper centers. This cooperative reductive-elimination step would not be accessible with a generic oxidant, which, again, is in agreement with available experimental data.
\end{abstract}

Direct catalytic $\mathrm{C}-\mathrm{H}$ activation is an appealing option for the synthesis of complex organic molecules. ${ }^{1}$ In contrast with the widely applied cross-coupling, ${ }^{2,3}$ it does not require the placement of a halide or any other leaving group in the position to be activated, and it improves atom economy by reducing the formation of waste products. When combined with the facile activation of an acidic $\mathrm{O}-\mathrm{H}$ or $\mathrm{N}-\mathrm{H}$ bond in the same molecule, direct $\mathrm{C}-\mathrm{H}$ activation opens the way to annulative coupling processes with great potential. ${ }^{4}$ However, the common need for an external oxidant has hindered the further development of such processes. If the two hydrogen atoms depart as protons, as is normally the case, the catalytic system will gain two electrons, which then have to be removed prior to a new catalytic cycle. Oxidative-coupling processes catalyzed by transition-metal complexes based on palladium, ${ }^{4 a, 5}$ rhodium, ${ }^{6}$ ruthenium $\mathrm{m}^{4 \mathrm{~b}, 7}$ and copper $^{8}$ have been reported, but the issue of the oxidant remains challenging.

Such reactions only seems to be efficient only with certain combinations of catalyst and oxidant. For instance, in reactions with the $\mathrm{Rh}(\mathrm{III}) / \mathrm{Rh}(\mathrm{I})$ redox pair as the catalyst, the oxidant of choice is usually the $\mathrm{Cu}^{\prime \prime}$ species $\mathrm{Cu}(\mathrm{OAc})_{2} \cdot \mathrm{H}_{2} \mathrm{O}$, which is reduced to a $\mathrm{Cu}^{\prime}$ complex during the reaction. ${ }^{9-11}$ The copper salt has been postulated to play an active role, ${ }^{11}$ but detailed mechanistic evidence is scarce. Jones and co-workers showed

\footnotetext{
[a] M.Sc. I. Funes-Ardoiz, Prof. F. Maseras

Institute of Chemicas Research of Catalonia (ICIQ), The Barcelona Institute of Science and Technology.

Avgda. Països Catalans, 16, Tarragona (43007), Catalonia, Spain

E-mail: fmaseras@iciq.es

[b] Prof. F. Maseras

Department de Química

Universitat Autònoma de Barcelona

Bellaterra (08193) Catalonia, Spain.
}

Supporting information for this article is given via a link at the end of the document. by UV-vis monitoring that a Rh diacetate species is formed in the presence of high acetate concentrations. ${ }^{12}$ The presence of additional acetate, introduced as $\mathrm{NaOAc}$, was also shown to be critical for the isolation of intermediates in the oxidative coupling of isoquinolones with alkynes. ${ }^{13}$ The oxidant role of the copper center has not been examined in detail in either of these experimental studies or in the computational analyse ${ }^{14}$ that have been carried out on related processes with $\mathrm{Rh}^{\mathrm{II}} / \mathrm{Cu}$ " systems. Herein, we computationally examine the specific role of $\mathrm{Cu}^{\prime \prime}$ in the mechanism of this process.

For our study, we chose one of the leading examples of this type of chemistry, an oxidative coupling reported by Miura, Satoh, and Ueura, which is shown in Scheme $1 .^{9}$ We were particularly interested in the effect of the oxidant on the selectivity of the reaction. ${ }^{9 b}$ When copper diacetate is used as oxidant, the isocoumarin $\mathbf{3}$ is formed in high yield. In contrast, when other oxidants, such as $\mathrm{Ag}\left(\mathrm{OAc}\right.$, are used, $\mathrm{CO}_{2}$ extrusion takes place, resulting in naphthalene derivative $\mathbf{4}$ as the major product.

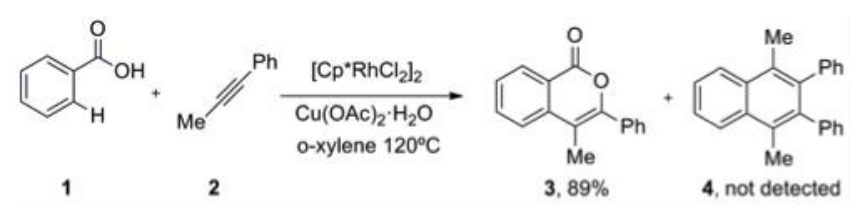

Scheme 1. Reported oxidative coupling between benzoic acid and alkyne. ${ }^{9}$

We studied the key steps in this process through geometry optimizations in ortho-xylene solution with the B97D functional. The only simplification from the real system consisted in replacing $\mathrm{Cp}^{*}$ by $\mathrm{Cp}$. A functional calibration showed that the results were similar to those obtained with MO6-D3, B3LYP,D3, BP86-D3, and $\omega B$ 97x-D (See the Supporting Information for full computational details and information on functional and basis set calibration).

The starting point for our mechanistic study was the proposal put forward by Miura, Satoh, and Ueura, which is summarized in Scheme 2. The reaction is initiated by protonation and displacement of one of the acetate ligands in the catalyst by benzoic acid. The second acetate participates in a concerted metallation deprotonation (CMD) step, which leads to cleavage of the ortho $\mathrm{C}-\mathrm{H}$ bond. ${ }^{15}$ Insertion of an alkyne into the Rh-C bond then leads to intermediate $\mathbf{5}$, which contains a sevenmembered cyclometalated ring. All of these steps leading up to intermediate $\mathbf{5}$ have been well characterized for related systems as having low barriers. This hypothesis was confirmed for this system by calculations that are shown in the Supporting Information. 


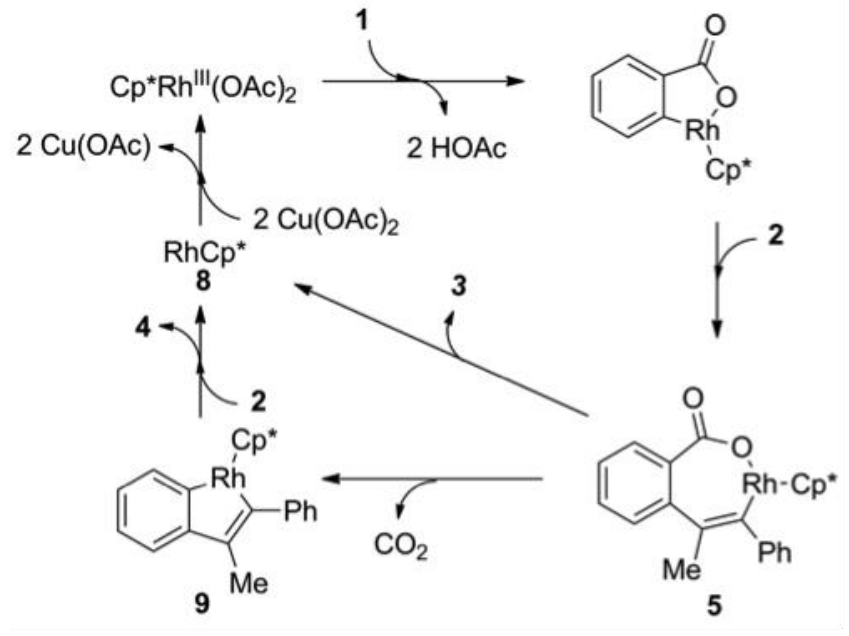

Scheme 2. Initial experimental proposal for the mechanism.

Intermediate $\mathbf{5}$ can evolve through one of the two alternative paths depicted in Scheme 2 to yield one of the two possible products, $\mathbf{3}$ or $\mathbf{4}$, and to regenerate the catalyst. We computationally studied the reactivity of $\mathbf{5}$ and found, to our surprise, that the path leading to $\mathrm{CO}_{2}$ extrusion is clearly favored as shown in the free energy profiles in Scheme 3. The direct reductive elimination pathway through Ts5-8, with geometrical features usually associated with these processes, ${ }^{16}$ has a free energy barrier of $13.0 \mathrm{kcal} / \mathrm{mol}$ relative to 5 . The value is modest, but clearly higher than that for $\mathrm{CO} 2$ extrusion through Ts5-9, which is $8.2 \mathrm{kcal} / \mathrm{mol}$ relative to 5 . We analyzed possible alternative paths that involve the coordination of acetic acid in the reaction medium, but the barrier for reductive elimination was even higher $(26.5 \mathrm{kcal} / \mathrm{mol}$, see the Supporting Information, Figure S3).

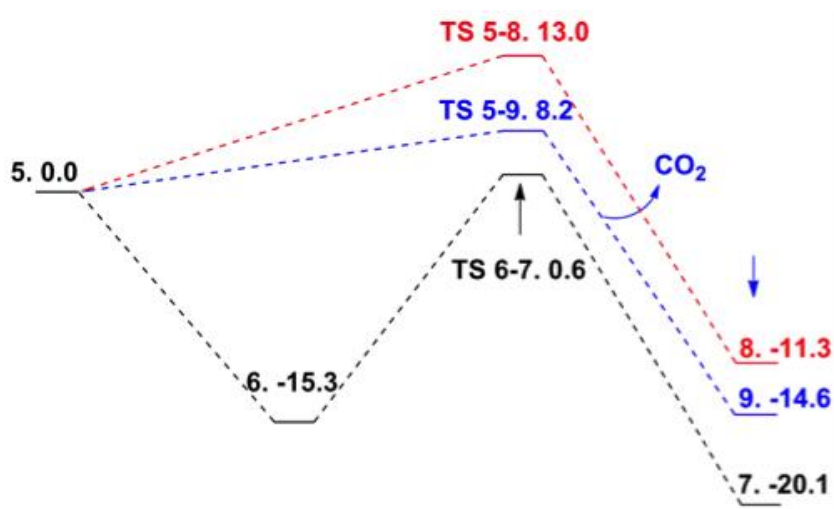

- Rh Red. Elim. Path.

- $\mathrm{CO}_{2}$ Extrusion Path.

Scheme 3. Free energy profile of the selectivity determining step in the reaction. All energies in $\mathrm{kcal} / \mathrm{mol}$ referred to the intermediate $\mathbf{5}$.

As intermediate 5 prefers to evolve towards $\mathrm{CO}_{2}$ extrusion, which contradicts the experimental observation, we decided to examine the possibility of the $\mathrm{Cu}^{\text {Il }}$ reducing agent interacting directly with 5 . This was not trivial, as $\mathrm{Cu}(\mathrm{OAc})_{2} \cdot \mathrm{H}_{2} \mathrm{O}$ does not exist primarily as a monometallic complex in solution. It is mainly in a dimetallic state, with the additional complication that the acetate ligand may exchange with other ligands, such as chloride (from the $\mathrm{Cp}^{*} \mathrm{RhCl}_{2}$ catalyst precursor), that are also available in the reaction mixture. We found that both $\left[\mathrm{Cu}(\mathrm{OAc})_{2}\left(\mathrm{H}_{2} \mathrm{O}\right)\right]_{2}$ and $\left[\mathrm{CuCl}(\mathrm{OAc})\left(\mathrm{H}_{2} \mathrm{O}\right)\right]_{2}$ form stable adducts with intermediate $\mathbf{5}$. The second of these adducts, with the chlorinated copper species, leads to the productive pathway for reductive elimination indicated in Scheme 3, with the highest free energy point in TS6-7 only $0.6 \mathrm{kcal} / \mathrm{mol}$ relative to 5 . This is much lower than the energy of the transition state of the alternative $\mathrm{CO} 2$ extrusion pathway.

Figure 1 shows the structure of the key transition state TS67 in this favored pathway. In this transition state, as well as in the related intermediates 6 and 7 (see the Supporting Infromation), there is a direct interaction between one of the carboxylate oxygen atoms and one of the copper centers, which

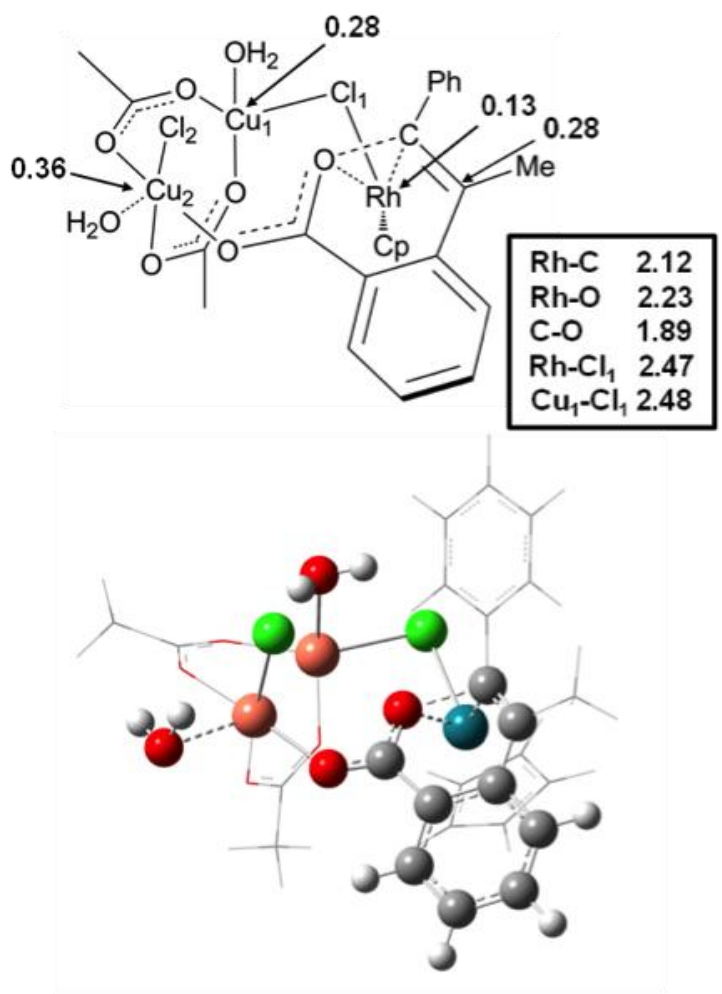

Figure 1. Key transition state (TS 6-7) of the cooperative reductive elimination pathway with spin densities and bon lengths (in A).

hinders $\mathrm{CO}_{2}$ extrusion. The structure clearly corresponds to $\mathrm{C}-\mathrm{O}$ formation, as indicated by the computed normal mode associated to the imaginary frequency and the C-O bond distance of $1.89 \AA$. The bridging position of the chlorine atom between $\mathrm{Cu}$ and $\mathrm{Rh}$, with $\mathrm{M}-\mathrm{Cl}$ distances of 2.47 and $2.48 \AA$, respectively, is also noteworthy. This bridge stabilizes the adduct and favors the electron transfer between the metal centers. 
Figure 1 also reports the spin densities, which provide information on the underlying features of this step. Two unpaired electrons are present because each initial $\mathrm{Cu}^{\text {II }}$ center contains one unpaired electron, and our calculations indicate that the dimer is most stable in a triplet spin state, as expected. The triplet lies $0.1 \mathrm{kcal} / \mathrm{mol}$ in energy below the open-shell singlet and $6.2 \mathrm{kcal} / \mathrm{mol}$ below the closed-shell singlet. The ground state for species 6, TS6-7, and 7 is a triplet. The open-shell singlet state for the key species TS6-7 is $1.1 \mathrm{kcal} / \mathrm{mol}$ above the triplet state with a qualitatively similar spin distribution and thus not discussed here. Concerning the triplet ground state, Figure 1 indicates the presence of significant spin density on rhodium (0.13) and one of the carbon atoms coming from the alkyne (0.28). Remarkably, the spin density on the two copper centers is only mildly higher $(0.28,0.36)$. The presence of spin density on the rhodium moiety of the adduct strongly suggests that the $R h^{\prime \prime \prime} / R^{\prime}$ description is not appropriate for the process taking place, as both of these oxidation states are associated with closed-shell distributions. Instead, we favour a scenario where $\mathrm{Rh}^{\text {III }}$ is partially reduced to $\mathrm{Rh}^{\text {"I }}$, and the other electron is transferred directly to the dicopper unit, with one $\mathrm{Cu}^{\text {Il }}$ and one $\mathrm{Cu}^{\prime}$ center. A similar scenario would be ontained with the openshell singlet spin state, but at a slightly higher energy (see the Supporting Information). This process therefore is an unusual reductive elimination, as summarized in Scheme 4. Only one of the two electrons from the anionic organic ligands goes to the adjacent metal center, while the other one is transferred directly to the final oxidant. We thus refer to this process as cooperative reductive elimination (CRE).

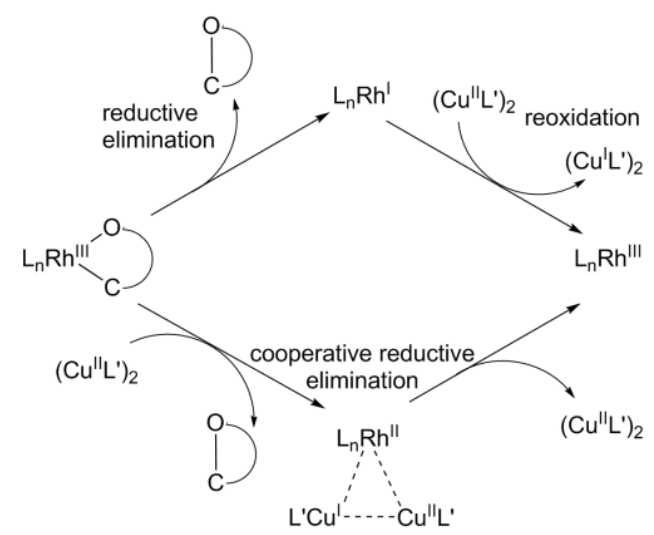

Scheme 4. Contrast between the conventional mechanism (reductive elimination plus reoxidation, above) and the cooperative reductive elimination mechanism (below).

The spin densities in 6 and $\mathbf{7}$ (figure S4) confirm the validity of this scenario. The total spin density in the two $\mathrm{Cu}$ centers decreases from 0.81 to 0.57 when going from 6 to 7 , while the density at $\mathrm{Rh}$ increases from 0.14 to 0.59 . One of the semioccupied molecular orbitals in TS 6-7 is also mostly located in the Rh moiety of the system (Figure S5), corroborating the CRE proposal. After the reductive elimination, the trimetallic complex 7 reorganizes; the organic product 3 is released (Scheme S6) and the Rh center then transfers one electron, with assistance from the $\mathrm{Cl}$ bridge atoms, to regenerate the initial catalyst $\left[\mathrm{CpRhCl}_{2}\right]$ and the $[\mathrm{Cu}(\mathrm{OAc})(\mathrm{H} 2 \mathrm{O})]_{2}$ waste product.
It follows from the description above that this mechanism can only operate with very specific reducing agents, which explains why oxidative coupling did not take place in the systems under study when other oxidizing agents were used instead of copper diacetate. ${ }^{9}$ The fact that some of the acetate ligands are replaced by chloride in the active transition state also agrees with the observed influence of acetate concentration on the nature of species in solution. ${ }^{12,13}$ The participation of more than one metal center in the reduction is reminiscent of the bimetallic reductive elimination observed in dinuclear $\mathrm{Pd}^{\mathrm{III}}$ complexes, ${ }^{17}$ but with substantial differences. The role of the additive is also different from that computationally determined for $\mathrm{AgOAc}$ and $\mathrm{CsF}$ in $\mathrm{Pd}{ }^{\text {II }} \mathrm{C}-\mathrm{H}$ activation chemistry. ${ }^{18}$

In conclusion, we have described a new cooperative reductive-elimination mechanism that satisfactorily explains the specific role of the copper diacetate oxidant in the rhodiumcatalyzed oxidative coupling of benzoic acid and alkynes. The oxidating agent participates directly in the reductive elimination process by taking one electron already in the reductiveelimination transition state itself. In this way, the rhodium oxidation state is never reached, which constitutes a clear deviation from the commonly observed reductive-elimination pattern at transition-metal centers. We consider that this cooperative reductive-elimination mechanism may be operating in other systems where external oxidazing agents are involved. Ongoing research in our group will aim to clarify the eventual generality of this mechanism.

\section{Acknowledgements}

Financial support from the ICIQ Foundation, MINECO (project CTQ2014-57661-R, and Severo Ochoa Excellence Accreditation 2014-2018 SEV-2013-0319) is gratefully acknowledged. I.F-A. acknowledges a fellowship from the ICIQ-Severo Ochoa program (Ref. SVP-2014-068662). We also thank Dr. Max García-Melchor and Dr. Nuno A.G. Bandeira for helpful discussions.

Keywords: Oxidative coupling - Density functional calculations - Reductive elimination $\cdot \mathrm{C}-\mathrm{C}$ coupling $\bullet$ Reaction mechanisms

[1] a) D. Alberico, M. E. Scott, M. Lautens, Chem. Rev. 2007, 107, 174 238; b) L. Ackermann, R. Vicente, A. R. Kapdi, Angew. Chem. Int. Ed. 2009, 48, 9792-9826; c) J. Wencel-Delord, F. Glorius, Nature Chem. 2013, 5, 369-375.

[2] Metal-Catalyzed Cross-Coupling Reactions, $2^{\text {nd }}$ Ed. (Eds.: A. de Meijere, F. Diedrich), Wiley-VCH, Weinheim, 2004.

[3] M. Garcia-Melchor, A. A. C. Braga, A. Lledos, G. Ujaque, F. Maseras, Acc. Chem. Res. 2013, 46, 2626-2634.

[4] a) T. Satoh, M. Miura, Chem. Eur. J. 2010, 16, 11212-11222; b) L. Ackermann, Acc. Chem. Res. 2014, 47, 281-295.

[5] a) T. W. Lyons, M. S. Sanford, Chem. Rev. 2010, 110, 1147-1169; b) D. C. Powers, T. Ritter, Acc. Chem. Res. 2012, 45, 840-850.

[6] a) D. A. Colby, A. S. Tsai, R. G. Bergman, J. A. Ellman, Acc. Chem. Res. 2012, 45, 814-825; b) B. Ye, N. Cramer, Acc. Chem. Res. 2015, 48, 1308-1318;

[7] P. B. Arockiam, C. Bruneau, P. H. Dixneuf, Chem. Rev. 2012, 112, 5879-5918. 
[8] X. -X. Guo, D. -W. Gu, Z. Wu, W. Zhang, Chem. Rev. 2015, 115, 1622-1651.

[9] a) K. Ueura, T. Satoh, M. Miura, Org. Lett. 2007, 9, 1407-1409; b) K. Ueura, T. Satoh, M. Miura, J. Org. Chem. 2007, 72, 5362-5367;

[10] a) D. R. Stuart, M. Bertrand-Laperle, K. M. N. Burgess, K. Fagnou, J. Am. Chem. Soc. 2008, 130, 16474-16475; b) T. K. Hyster, T. Rovis, J Am. Chem. Soc. 2010, 132, 10565-10569; c) L. Huang, Q. Wang, J. Qi X. Wu, K. Huang, H. Jiang, Chem. Sci. 2013, 4, 2665-2669; d) J. Shi, Y. Yan, L. Qiu, H. E. Xu, W. Yi, Chem. Commun. 2014, 50, 6483-6486; e) J. Zheng, S. -B. Wang, C. Zheng, S. L. You, J. Am. Chem. Soc. 2015 134, 4880-4883 ; f) R. B. Dateer, S. Chang, J. Am. Chem. Soc. 2015 137, 4908-4911; g) A. M. Martínez, J. Echavarren, I. Alonso, N. Rodriguez, R. Gómez-Arrayás, J. C. Carretero, Chem. Sci. 2015, 6 5802-5814.

[11] a) L. Li, W. W. Brennessel, W. D. Jones, J. Am. Chem. Soc. 2008, 130, 12414-12419; b) F. W. Patureau, J. Wencel-Delord, F. Glorius, Aldrichimica Acta 2012, 2, 31-41.

[12] L. Li, W. W. Brennessel, W. D. Jones, Organometallics 2009, 28, 3492 3500 ;

[13] N. Wang, B. Li, H. Song, S. Xu, B. Wang, Chem. Eur. J. 2013, 19, 358 364.
[14] a) L. Xu, Q. Zhu, G. Huang, B. Cheng, Y. Xia, J. Org. Chem. 2012, 77 3017-3024; b) N. Quiñones, A. Seoane, R. García-Fandiño, J. L. Mascareñas, M. Gulías, Chem. Sci. 2013, 4, 2874-2879; c) D. L. Davies, C. E. Ellul, S. A. Macgregor, C. L. McMullin, J. Am. Chem. Soc. 2015, 137, 9659-9669; d) J. Jiang, R. Ramozzi, K. Morokuma, Chem. Eur. J. 2015, 21, 11158-11164.

[15] a) D. L. Davies, S. M. A. Donald, O. Al-Duaij, S. A. Macgregor, M. Pölleth, J. Am. Chem. Soc. 2006, 128, 4210-4211. b) D. GarciaCuadrado, P. de Mendoza, A. A. C. Braga, F. Maseras, A. M Echavarren J. Am. Chem. Soc. 2007, 129, 6880-6886; c) S. I. Gorelsky, D. Lapointe, K. Fagnou, J. Am. Chem. Soc. 2008, 130, 10848-10849.

[16] a) V. P. Ananikov, D. G. Musaev, K. Morokuma, J. Am. Chem. Soc. 2002, 124, 2839-2852; b) M. Perez-Rodriguez, A. A. C. Braga, M. Garcia-Melchor, M. H. Perez-Temprano, J. A. Casares, G. Ujaque, A. R. de Lera, R. Alvarez, F. Maseras, P. Espinet, J. Am. Chem. Soc. 2009, 131, 3650-3657.

[17] D. C. Powers, D. Benitez, E. Tkatchouk, W. A. Goddard III, T. J. Ritter, J. Am. Chem. Soc. 2010, 132, 14092-14103.

[18] M. Anand, R. B. Sunoj, H. F. Schaefer, J. Am. Chem. Soc. 2014, 136, 5535-5538. 


\section{Entry for the Table of Contents}

\section{COMMUNICATION}

Joint effort. The reaction between benzoic acid and methylphenylacetylene to form an isocoumarin is catalyzed by $\mathrm{Cp}^{\star} \mathrm{Rh}(\mathrm{OAc})_{2}$ in the presence of $\mathrm{Cu}(\mathrm{OAc}) 2(\mathrm{H} 2 \mathrm{O})$ as the oxidant. Its mechanism was elucidated by DFT calculations with the B97D functional, which showed that the overall transformation proceeds by cooperative reductive elimination with a transition state containing both rhodium and copper centers.
Author(s), Corresponding Author(s)*

Page No. - Page No.

Cooperative Reductive Elimination: The Missing Piece in the Oxidative Coupling Mechanistic Puzzle 